\title{
Predictors of Teacher Efficacy for Inclusive Practice in Pre-service Teachers
}

\author{
Jacqueline A. Specht \\ The University of Western Ontario \\ Jamie L. Metsala \\ Mount Saint Vincent University
}

\begin{abstract}
Teachers who show high teacher efficacy affect student achievement positively. Teaching is sometimes seen as an overwhelming profession because of classroom diversity and expectations placed on teachers. It is important to bring beginning teachers to the point at which they feel they are capable and will be more emotionally equipped to take on the stressors of the classroom. The current study focused on predicting preservice teachers' efficacy for inclusive practice from variables found to be important in the literature: gender, inclusion-related beliefs, and experiences with individuals with disabilities. Participants consisted of 1,026 students completing the in-faculty component of their pre-service program in 9 faculties of education across Canada. They completed the Teacher Efficacy for Inclusive Practice survey and the Beliefs about Learning and Teaching Questionnaire. All teacher candidates appeared to benefit from experience with people with disabilities. General findings indicated more positive inclusive beliefs for women than men and for preservice teachers in elementary than in secondary programs. Important differences emerged, however, concerning which beliefs contributed to each area of teacher efficacy for secondary as compared to elementary programs. Results are discussed in terms of issues to consider in initial teacher education programs.
\end{abstract}


The Canadian Charter of Rights and Freedoms (Section 15, Equality Rights) addresses the issue of providing education on an equal basis for all students regardless of difference. Education in Canada is mandated provincially; therefore, different jurisdictions across the country provide a varied response. A province like New Brunswick, for example, mandates that for public education, all children will attend their neighbourhood school and learn alongside their peers. There are no special schools, classes, or courses (Province of New Brunswick, 2016). In Ontario, however, a range of placements is available from special schools to education in the neighbourhood schools with same-age peers (Ontario Ministry of Education, 2017). Regardless of these differences, all jurisdictions value inclusion as the first choice for students with disabilities. As a result, most students with identified disabilities are educated in their neighbourhood schools with their same-age peers. Teachers in Canada are qualified first to be general education teachers. They are then required to take further certification to become special education teachers. As a result, all teachers attend a faculty of education for their initial teacher education program and these are the people of interest in the current paper.

\section{Importance of Teachers' Beliefs and Efficacy}

Teachers' beliefs have a strong influence on their practice (Kavanoz,Yüksel, \& Varol, 2017). Beliefs have been defined as "psychologically held understandings, premises, or propositions about the world that are felt to be true" (Richardson, 2003, p. 2). Several studies have found that positive teacher beliefs toward inclusion can be the most influential factor in the development of inclusive schools and classrooms (Jordan \& Stanovich, 2003; Sharma, Forlin, C., \& Loreman, 2008; Stanovich \& Jordan, 2004). On the other hand, resistance to inclusion is one of the biggest barriers to creating inclusive school environments (Avramidis \& Norwich, 2002; Brighton, 2003; McGhieRichmond, Irvine, Loreman, Cizman, \& Lupart, 2013). For successful school inclusion, it is necessary to ensure that our teachers have the belief that all children belong in the neighbourhood school and the belief that they can teach them.

Jordan and colleagues developed a research program to investigate the relationship between beliefs about ability and practice in inclusive education classrooms (see Jordan, Glenn, \& McGhie-Richmond, 2010, for overview). The outcomes of their program confirmed the understanding that when teachers use instructional techniques that are effective for students with disabilities, they are effective for overall student achievement. Beliefs were found to be extremely influential in the development of effective teaching. Teachers who take responsibility for teaching students with disabilities tend to believe that ability is a malleable rather than a fixed trait and believe that learning difficulties are a result of instructional techniques that they can control. Most importantly, they found that these general epistemological beliefs about learning are linked to the instructional decisions that teachers make about how to teach and whom to teach (Jordan, 2018; Jordan et al., 2010). It is extremely important that teacher education programs cultivate beliefs that learning is not fixed and that there are many strategies that teachers can use to help all students learn. 
Bandura (1994) defined self-efficacy as people's beliefs about their abilities to accomplish difficult tasks in the future. People with high self-efficacy see difficult tasks as challenges to accept, whereas those with low self-efficacy see these tasks as ones to avoid. Woolfolk Hoy and colleagues (e.g., Woolfolk Hoy, Hoy, \& Davis, 2009) extended this work to teachers. Teachers with a high sense of efficacy believe that they can help all students learn, even those who struggle the most. Teacher efficacy has been shown to be influential in teacher professional commitment (Klassen et al., 2013), resilience (Bobek, 2009), teacher performance and student achievement (Caprara, Barbaranelli, Steca, \& Malone, 2006; Holzberger, Philipp, Kunter, 2013; Klassen \& Durksen, 2014), and job satisfaction (Høigaard, Giske, \& Sundsli, 2012). It has also been shown that teacher efficacy can influence classroom behaviours, particularly with regard to learners with additional needs (Palmer, 2006).

In a synthesis of 40 years of research with pre-service and in-service teachers across different grade levels and countries, findings indicated that teachers who show high efficacy affect student achievement positively (Zee \& Koomen, 2016). They are also less stressed, experience less emotional exhaustion, and are generally less burned out than teachers with low efficacy. These findings are extremely important in light of our knowledge that $33 \%$ of our teachers leave the profession in the first 5 years of teaching (Shaw \& Newton, 2014). Teaching is currently seen as an overwhelming profession and it is important to bring beginning teachers to the place where they feel they are capable and will be more emotionally equipped to take on the stressors of the classroom.

Teacher efficacy for inclusive practice is a newer area of research. As our classrooms become more inclusive, it is important that teachers feel that they are capable of teaching in these settings. According to Bandura (1977), knowing that certain actions result in outcomes is useless if people do not believe that they have the ability to produce such actions-so teachers may believe that inclusion is better for students with disabilities, but if they do not believe that they can teach those students, they will not be successful. Sharma, Loreman, and Forlin (2012) recognized the need for further investigations in this area. In searching the literature, they determined that three core areas of competence are required to be an effective inclusive educator. It is important that teachers have a firm grasp of the content they teach and of the pedagogical practices to do so. It is also important that they are equipped to manage classroom environments and the behaviours within their classrooms. Finally, it is necessary that they have the skills to work collaboratively with the other adults in the lives of the children (e.g., parents, paraprofessionals). Teachers need to feel efficacious in each core competency of inclusive education (Sharma et al., 2012).

\section{Teacher Beliefs and Efficacy in Elementary and Secondary Teachers}

Overall, research has reported less positive attitudes and beliefs about inclusive education for practising secondary than for elementary teachers (e.g., McGhie-Richmond et al., 2013; Todorovic, Stojiljkovic, Djigic, \& Ristanic, 2012). For example, Chiner and Cardona (2013) found that elementary teachers in Spain had more positive attitudes toward inclusion than secondary teachers; only $30 \%$ of teachers believed that inclusion was possible in secondary education. Woodcock and Hardy (2017) reported that mid- 
career secondary teachers (11-20 years teaching experience) in particular, were less likely to report that inclusive classrooms were an effective way to teach all students; however, early career elementary and secondary teachers in their study were equally positive about inclusive education for all students. In a study on teamwork and inclusive classroom practices with general and special educators in Germany, researchers found elementary school teachers reported more positive experiences than secondary school teachers (Gebhardt, Schwab, Krammer, \& Gegenfurtner; 2015).

Previous research also found differences between elementary and secondary pre-service teachers' beliefs about inclusive practices. In a pan-Canada study, Specht et al. (2016) found that elementary pre-service teachers had more inclusive beliefs than secondary pre-service teachers. The elementary pre-service teachers had lower scores on scales measuring beliefs concerning students' abilities as fixed traits, teachers as the transmitters of knowledge, and high grades and external rewards as the critical student motivators. Furthermore, elementary teachers believed in more student-centred classroom practices, and had higher teacher efficacy for collaborative practices for inclusive education. Teacher efficacy for inclusive practices has been one focus of research with pre-service teachers; however, research studies frequently collapse results across program level (i.e., elementary and secondary pre-service teachers; e.g., Peebles \& Mendaglio, 2014). Furthermore, given the frequent reports that a higher proportion of secondary than elementary teachers are male, analyses examining these program-level differences have frequently been confounded by gender differences (e.g., Chiner \& Cardona, 2013; Specht et al., 2016). The current study examined possible interactions between program level and gender.

Teacher preparation programs are in a unique position to address concerns about teacher efficacy for inclusive practices by encouraging the development of positive beliefs and by equipping teachers with the skills they need (Miesera \& Gebhardt, 2018; Sokal, Woloshyn, \& Funk-Unrau, 2013; Specht et al., 2016). It is necessary for university programs to remediate feelings of unpreparedness (Sharma \& Sokal, 2015; Smith \& Tyler, 2011); a better understanding of the teacher efficacy of elementary and secondary pre-service teachers will help in this goal.

\section{Rationale for Current Study}

Few studies have focused on both the teacher efficacy and teaching beliefs of preservice teachers for inclusion (Peebles \& Mendaglio, 2014; Specht et al., 2016), especially within a comprehensive framework examining factors found to contribute to both constructs within the same population. In a pan-Canadian study of pre-service teachers at the end of their teacher education program, Specht et al. found that, overall, teacher candidates reported feeling a high sense of teacher efficacy in terms of collaboration, managing behaviour, and instruction. Their responses indicated an orientation to believing that ability is malleable, and they felt strongly that teachers should use student-centred learning. These pre-service teachers were more moderate in their beliefs about teachers being the transmitters of knowledge and that high marks are what motivates students to learn.

Specht et al. (2016) determined group differences based on demographic variables for inclusion-related beliefs and teacher efficacy. They reported the following findings: 
Pre-service teachers planning to teach in the elementary stream were more positive toward inclusion than those planning to teach in the secondary stream; women tended to have more inclusive beliefs than men; and those who had friends with disabilities tended to be more inclusive than those who did not.

The current study focused on predicting pre-service teachers' efficacy from variables found to be important in the literature: gender, inclusion-related beliefs, and experiences with individuals with disabilities. A regression-based logic was used so that these factors could be examined in concert, rather than in isolation (e.g., Specht et al., 2016). Furthermore, predictors of teacher efficacy were examined separately for each program level, as previous research has indicated significant differences on inclusion-related measures for elementary as compared to secondary pre-service and practising teachers (e.g., Chiner \& Cardona, 2013; Specht et al., 2016; Todorovic et al., 2012). Through carrying out these analyses, we sought to determine the unique contributions that beliefs make to the efficacy of pre-service teachers in elementary as compared to secondary programs. Furthermore, to overcome a limitation of previous research that has confounded gender and program level, we examined group differences with both factors in the same analysis.

\section{Method}

\section{Participants}

Participants consisted of 1,026 students completing the in-faculty component of their pre-service program in nine faculties of education across Canada, and enrolled in an elementary $(\mathrm{K}-6)$ or secondary (7-12) teaching program. There were 604 students enrolled in elementary programs (530 females), and the group had a mean age of 25.96 years (range 21-52 years). There were 422 participants enrolled in secondary programs (244 females), with a mean age of 26.73 years (range $=21-56$ years).

\section{Measures}

On a demographic questionnaire, participants provided information on their age, gender, length of program, and the school grades for which they were being prepared to teach. Furthermore, participants responded to the statement "I have encountered people with disabilities in the following ways (check all that apply)"; response options included a category for "friend" and for "work/volunteer." Participants also indicated that their length of "experience teaching a student with an exceptionality" was none, 1-30 days, or more than 30 full days. Participants completed the Teacher Efficacy for Inclusive Practice questionnaire (TEIP; see Sharma et al., 2012), which assessed their feelings of teacher efficacy as their teacher education programs concluded. Reponses on each of the 18 items on this scale are indicated on a 6-point Likert scale (higher scores indicate higher self-efficacy). Sharma et al. reported three factors on this self-efficacy scale: Efficacy in Collaboration, which measures the participants' self-perceptions of working with parents and colleagues in the schools; Efficacy in Managing Behaviour, referring to sense of competence in dealing with disruptive behaviours in the classroom; and Efficacy to Use Inclusive Instruction, which refers to the use of teaching strategies consistent with 
the inclusion of all learners. Each scale has been found to have high internal reliability, with Cronbach's alpha of 0.85, 0.85, and 0.93, respectively (Sharma et al., 2012).

Participants' beliefs about their roles and responsibilities for including students with exceptional needs in the classroom, including those with disabilities or at risk for academic failure, were measured with the Beliefs About Learning and Teaching Questionnaire (BLTQ, see Glenn, 2018). Responses for the 20 items were on a 6-point Likert scale, and four factors are reported: Student-Centred Instruction, with high scores representing beliefs that students' needs and the learning process are the focus of teachers' instruction-based decisions; Teacher-Controlled Instruction, for which high scores indicate beliefs that a teacher's focus is on transmitting information; EntityIncrement, with high scores ${ }^{1}$ indicating beliefs that students' learning ability is a fixed rather than a malleable trait that is relatively impervious to good instruction; and Attaining Standards, for which high scores represent beliefs that external rewards, such as high grades, are primary motivators for students. A perspective consistent with a positive outlook on inclusion would include high scores on the Student-Centred scale, and low scores on and Entity-Increment, Teacher Controlled, and Attaining Standards scales. Cronbach's alpha for the four scales are: .66, .73, .64, and .70, respectively (Glenn, 2018). These values are considered acceptable (Bacon, 2004).

\section{Procedures}

Participants completed the printed surveys during a class, near the conclusion of their initial teacher education program. Procedures were implemented to ensure that participants' instructors were not involved in data collection, and pre-service teachers who did not wish to participate handed in blank surveys or left the classroom during this time period.

\section{Results}

Participants' scores from each of the TEIP and BLTQ scales were normally distributed, with only the BLTQ Entity-Increment scale showing a mild positive skewness of 1.39 for the Elementary group and 1.1 for the Secondary group (Tabachnick $\&$ Fidell, 2007). Missing data were not replaced, so the number of participants across analyses varies slightly. All reported test statistics are significant at $p<.05$, unless otherwise indicated.

\section{Gender Differences for Each of Elementary and Secondary Programs}

We completed a series of MANOVAs to examine gender- and program-level differences and any interaction between these factors, as comparisons have been confounded in previous research. A MANOVA for the four BLTQ scales showed a main effect of gender $F(4,986)=7.39$; Wilks' $\Lambda=0.97$, partial $\eta^{2}=.03$, and a main effect of program level $F(4,986)=14.28$; Wilks' $\Lambda=0.95, \eta^{2}=.06$; there was no interaction of gender $\times$ program level (see Table 1 for cell means and standard deviations). There was

${ }^{1}$ The E-I scale of the BLTQ as described by Glenn $(2018$, p. 59) is typically reverse-scored. In this study, however, the E-I scale was not reverse-scored. 
no effect of gender on the Student Centred scale, and on the three remaining scales, women scored lower (indicating more inclusive beliefs) than men. For each of the four scales, elementary pre-service teachers had more inclusive beliefs than secondary preservice teachers.

Table 1

Means and Standard Deviations for Teacher Beliefs and Teacher Efficacy Questionnaires

\begin{tabular}{|c|c|c|c|c|c|c|c|c|}
\hline \multicolumn{9}{|c|}{ Beliefs About Teaching and Learning Questionnaire } \\
\hline & \multicolumn{4}{|c|}{ Elementary } & \multicolumn{4}{|c|}{ Secondary } \\
\hline & \multicolumn{2}{|c|}{ Females } & \multicolumn{2}{|c|}{ Males } & \multicolumn{2}{|c|}{ Females } & \multicolumn{2}{|c|}{ Males } \\
\hline \multirow[t]{2}{*}{$N$} & \multicolumn{2}{|c|}{510} & \multicolumn{2}{|c|}{74} & \multicolumn{2}{|c|}{238} & \multicolumn{2}{|c|}{171} \\
\hline & $M$ & $S D$ & M & $S D$ & $M$ & $S D$ & $M$ & $S D$ \\
\hline $\mathrm{TC}$ & 2.88 & .72 & 3.00 & .75 & 3.07 & .67 & 3.39 & .70 \\
\hline El & 1.84 & .76 & 1.85 & .90 & 1.98 & .80 & 2.21 & .95 \\
\hline SC & 4.90 & .55 & 4.94 & .54 & 4.79 & .60 & 4.71 & .60 \\
\hline AS & 2.68 & .79 & 3.03 & .83 & 3.12 & .78 & 3.42 & .88 \\
\hline \multicolumn{9}{|c|}{ Teacher Efficacy for Inclusive Practice Questionnaire } \\
\hline \multirow[t]{2}{*}{$N$} & \multicolumn{2}{|c|}{530} & \multicolumn{2}{|c|}{74} & \multicolumn{2}{|c|}{244} & \multicolumn{2}{|c|}{178} \\
\hline & M & $S D$ & M & $S D$ & $M$ & $S D$ & M & $S D$ \\
\hline Coll & 4.80 & .62 & 4.85 & .63 & 4.70 & .65 & 4.62 & .65 \\
\hline MB & 4.50 & .60 & 4.84 & .63 & 4.52 & .59 & 4.68 & .65 \\
\hline Instr & 4.93 & .52 & 5.09 & .51 & 4.96 & .53 & 4.89 & .53 \\
\hline
\end{tabular}

Note: TC = Teacher Controlled; EI = Entity-Increment; SC = Student Centred; AS = Attaining Standards. Coll = Collaboration; MB = Managing Behaviour; Instr = Instruction.

A similar MANOVA for the three TEIP scales showed a main effect of gender $F(3,1020)=13.61$; Wilks' $\Lambda=0.96$, partial $\eta^{2}=.01$, and program level $F(3,1020)=3.40$; Wilks' $\Lambda=0.99$, partial $\eta^{2}=.04$, and a significant gender $\times$ program level interaction $F(3,1020)=3.06$; Wilks' $\Lambda=0.99$, partial $\eta^{2}=.01$. See Table 1 for scale means and standard deviations. Univariate tests revealed that there were no group differences for the Collaboration scale. For the Managing Behavior scale, men had higher teacher efficacy than women. For the Instruction scale, men in the Elementary group had higher teacher efficacy than each of the other three groups.

\section{Contributions to Pre-service Teachers' Efficacy for Inclusive Practices}

Zero-order correlations are shown separately for elementary and secondary preservice teachers in Table 2. For both elementary and secondary pre-service teachers, Student Centred beliefs are significantly correlated with aspects of teacher efficacy; however, for secondary teachers, the Entity-Increment and the Attaining Standards scales on the BLTQ are also significantly related to aspects of teacher efficacy. 
Table 2

Correlations of Major Variables in Study

\begin{tabular}{|c|c|c|c|c|c|c|c|c|c|c|c|c|}
\hline & Measure & 1 & 2 & 3 & 4 & 5 & 6 & 7 & 8 & 9 & 10. & 11. \\
\hline 1 & Gender & & -.02 & .02 & .07 & $-.24^{* *}$ & $-.14^{* *}$ & .06 & $-.18^{* *}$ & .06 & $-.14^{* *}$ & .06 \\
\hline 2 & Exp. Friend & -.02 & & .08 & $.21^{* *}$ & -.09 & $-.13^{* *}$ & .04 & -.06 & $.19^{* *}$ & .07 & $.12^{* *}$ \\
\hline 3 & Exp. Work & -.01 & -.05 & & $.13^{* *}$ & -.01 & $-.13^{* *}$ & -.05 & -.01 & .04 & .07 & .02 \\
\hline 4 & Exp. Teach & -.05 & $.09^{*}$ & $.16^{\star *}$ & & -.04 & .03 & -.04 & -.01 & $-.16^{\star *}$ & $.12^{* \star}$ & $.10^{*}$ \\
\hline 5 & BLTQ.TC & -.07 & -.06 & $-.09^{*}$ & $-.12^{*}$ & & $.46^{\star *}$ & $-.14^{\star *}$ & $.42^{* *}$ & -.06 & .025 & -.06 \\
\hline 6 & BLTQ.EI & -.01 & -.06 & -.02 & -.08 & $.38^{* *}$ & & $-.20^{\star *}$ & $.28^{* *}$ & $-.16^{\star *}$ & -.07 & $-.21^{* *}$ \\
\hline 7 & BLTQ.SC & -.02 & .04 & $.14^{\star *}$ & .06 & $-.18^{\star *}$ & $-.17^{* *}$ & & & $.13^{*}$ & .03 & $.16^{* *}$ \\
\hline 8 & BLTQ.AS & $-.14^{*}$ & $-.08^{*}$ & -.03 & -.06 & $.43^{* *}$ & .32 & $-.12^{\star *}$ & & -.02 & $.11^{*}$ & -.02 \\
\hline 9 & TEIP.Coll & -.04 & $.11^{\star *}$ & $.13^{* *}$ & $.17^{* *}$ & -.06 & -.02 & $.23^{* *}$ & .05 & & $.45^{\star *}$ & $.69^{* *}$ \\
\hline 10 & TEIP.MB & $-.19^{* *}$ & $.09^{*}$ & $.09^{*}$ & $.20^{* *}$ & -.03 & .01 & $.14^{\star *}$ & .06 & $.59^{* *}$ & & $.48^{\pi x}$ \\
\hline 11 & TEIP.Instr & $-.10^{*}$ & .06 & $.13^{* *}$ & $.10^{*}$ & -.03 & -.01 & $.20^{* *}$ & .01 & $.66^{* *}$ & $.58^{* *}$ & \\
\hline
\end{tabular}

Note: ${ }^{* *} p<.01 ;{ }^{*} p<.05$. Correlations for the Secondary participants are above the diagonal and those for Elementary participants are below the diagonal. Exp. Friend = experience with individuals with exceptionalities through friendship; Exp. Work = experience with individuals with exceptionalities through work; Exp. Teach= length of time teaching individuals with exceptionalities. BLTQ = Beliefs About Learning and Teaching Questionnaire; TC = Teacher Controlled; EI = Entity-Increment; SC = Student Centred; AS = Attaining Standards; TEIP = Teacher Efficacy for Inclusive Practice questionnaire; Coll = Collaboration; MB = Managing Behaviour; Instr = Instruction. 
In order to examine which variables account for unique variance in elementary and secondary pre-service teachers' efficacy, a series of regression analyses were performed. The predictor variables were the four scales of the BLTQ, as well as gender, experience with individuals with disabilities through friendship (referred to below as Friendship) and through work or volunteering (Work), and teaching individuals with exceptionalities (Teach). We first examined contributions to pre-service teachers' efficacy for Collaboration (see Table 3). For elementary pre-service teachers, each of the experience variables was significant, as were the Student Centred and Attaining Standards scales of the BLTQ; the equation accounted for $12 \%$ of the total variance. For secondary preservice teachers, the experience variables of Friendship and Teach were significant contributors, as was the Entity-Increment scale of the BLTQ. Overall, 9\% of the variance was accounted for in the regression.

Table 3

Regressions Predicting Pre-service Teachers' Self-Efficacy for Collaboration

\begin{tabular}{lccccccc}
\hline & \multicolumn{3}{c}{ ELEMENTARY } & & \multicolumn{3}{c}{ SECONDARY } \\
\cline { 2 - 4 } \cline { 6 - 8 } Predictor & $\boldsymbol{\beta}$ & SE $\boldsymbol{\beta}$ & Final $\boldsymbol{\beta}$ & & $\boldsymbol{\beta}$ & SE $\boldsymbol{\beta}$ & Final $\boldsymbol{\beta}$ \\
\hline Gender & -.01 & .33 & -.01 & & .06 & .07 & .05 \\
Exp. Friend & .15 & .07 & $.12^{*}$ & & .19 & .07 & $.15^{*}$ \\
Exp. Work & .15 & .05 & $.09^{*}$ & & .04 & .09 & .02 \\
Exp. Teach & .15 & .07 & $.17^{*}$ & & .14 & .05 & $.14^{*}$ \\
BLTQ.TC & -.03 & .04 & -.04 & & .04 & .06 & .05 \\
BLTQ.EI & .01 & .04 & .02 & & -.12 & .04 & $-.16^{*}$ \\
BLTQ.SC & .25 & .04 & $.23^{*}$ & & .09 & .06 & .09 \\
BLTQ.AS & .08 & .05 & $.11^{*}$ & & .01 & .04 & .02 \\
\hline
\end{tabular}

Note. ${ }^{*} p<.05 ; R^{2}=.12$ for Elementary; $R^{2}=.09$ for Secondary. Exp. Friend = experience with individuals with exceptionalities through friendship; Exp. Work = experience with individuals with exceptionalities through work; Exp. Teach $=$ length of time teaching individuals with exceptionalities. BLTQ $=$ Beliefs About Learning and Teaching Questionnaire; TC = Teacher Controlled; EI = Entity-Increment; SC = Student Centred; AS = Attaining Standards.

The same predictor variables were used to examine contributions to teacher efficacy for Managing Behavior (see Table 4). For elementary pre-service teachers, each of gender, Friendship, Work, and the Student Centred scale on the BLTQ were significant contributors, accounting for $11 \%$ of the total variance. For secondary pre-service teachers, gender, Teach, and the Entity-Increment and Attaining Standards scales of the BLTQ were significant contributors, accounting for $7 \%$ of the total variance.

Finally, contributors to teacher efficacy for Inclusive Instruction were examined (see Table 5). For elementary pre-service teachers, Work and Teach were significant contributors, as was the Student Centred scale on the BLTQ. For the secondary preservice teachers, Teach and the Entity-Increment and Student Centred scales were significant contributors. The equations accounted for $7 \%$ and $10 \%$ of the variance in preservice teachers' efficacy for instruction for elementary and secondary pre-service teachers, respectively. 
Table 4

Regressions Predicting Pre-service Teachers'

Self-Efficacy for Managing Behavior

\begin{tabular}{lccccccc}
\hline \multirow{2}{*}{ Predictor } & \multicolumn{3}{c}{ Elementary } & & \multicolumn{3}{c}{ Secondary } \\
\cline { 2 - 4 } \cline { 6 - 8 } & $\boldsymbol{\beta}$ & SE $\boldsymbol{\beta}$ & Final $\boldsymbol{\beta}$ & & $\boldsymbol{\beta}$ & SE $\boldsymbol{\beta}$ & Final $\boldsymbol{\beta}$ \\
\hline Gender & -.30 & .07 & $-.16^{*}$ & & -.20 & .06 & $-.16^{*}$ \\
Exp. Friend & .11 & .05 & $.09^{*}$ & & .01 & .06 & .01 \\
Exp. Work & .10 & .07 & .06 & & .06 & .09 & .04 \\
Exp. Teach & .17 & .04 & $.20^{*}$ & & .13 & .05 & $.14^{*}$ \\
BLTQ.TC & -.02 & .04 & -.02 & & -.01 & .05 & -.01 \\
BLTQ.EI & .04 & .04 & .05 & & -.10 & .04 & $-.14^{*}$ \\
BLTQ.SC & .15 & .05 & $.14^{*}$ & & .04 & .05 & .04 \\
BLTQ.AS & .05 & .04 & .08 & & .10 & .04 & $.14^{*}$ \\
\hline
\end{tabular}

Note. ${ }^{*} p<.05 ; R^{2}=.11$ for Elementary; $R^{2}=.07$ for Secondary. Exp. Friend = experience with individuals with exceptionalities through friendship; Exp. Work = experience with individuals with exceptionalities through work; Exp. Teach = length of time teaching individuals with exceptionalities. BLTQ = Beliefs About Learning and Teaching Questionnaire; TC = Teacher Controlled; EI = Entity-Increment; SC = Student Centred; AS = Attaining Standards.

Table 5

Regressions Predicting Pre-service Teachers' Self-Efficacy for Instruction

\begin{tabular}{lccccccc}
\hline & \multicolumn{3}{c}{ Elementary } & & \multicolumn{3}{c}{ Secondary } \\
\cline { 2 - 4 } \cline { 6 - 8 } Predictor & $\boldsymbol{\beta}$ & SE $\boldsymbol{\beta}$ & Final $\boldsymbol{\beta}$ & & $\boldsymbol{\beta}$ & SE $\boldsymbol{\beta}$ & Final $\boldsymbol{\beta}$ \\
\hline Gender & -.12 & .07 & -.08 & & .04 & .05 & .04 \\
Exp. Friend & .06 & .04 & .06 & & .09 & .05 & .08 \\
Exp. Work & .15 & .06 & $.10^{*}$ & & -.04 & .07 & -.02 \\
Exp. Teach & .07 & .03 & $.09^{*}$ & & .09 & .04 & $.10^{*}$ \\
BLTQ.TC & -.01 & .03 & -.01 & & .05 & .05 & .06 \\
BLTQ.EI & .01 & .03 & .01 & & -.16 & .03 & $-.26^{*}$ \\
BLTQ.SC & .18 & .04 & $.18^{*}$ & & .10 & .05 & $.11^{*}$ \\
BLTQ.AS & .02 & .03 & .03 & & .03 & .04 & .04 \\
\hline
\end{tabular}

Note. ${ }^{*} p<.05 . R^{2}=.07$ for Elementary; $R^{2}=.10$ for Secondary. Exp. Friend = experience with individuals with exceptionalities through friendship; Exp. Work = experience with individuals with exceptionalities through work; Exp. Teach = length of time teaching individuals with exceptionalities. BLTQ = Beliefs About Learning and Teaching Questionnaire; $\mathrm{TC}=$ Teacher Controlled; $\mathrm{EI}=$ Entity-Increment; SC = Student Centred; AS = Attaining Standards. 


\section{Discussion}

One goal of this research was to examine gender differences in pre-service teachers' efficacy and inclusive beliefs without confounding program level, as seen in some previous research. A second goal of the research was to assess what factors contributed unique variance to elementary and secondary pre-service teachers' efficacy for inclusive educational practices.

\section{Gender Differences}

We found more positive inclusive beliefs for women than for men, regardless of program level. A notable exception was that men and women had equivalent beliefs concerning the importance of student-centred practices in the classroom. In addition, we found that pre-service teachers in elementary programs had more inclusive beliefs than those in secondary programs, and this was regardless of gender. Concerning teacher efficacy, men had higher ratings than women for managing behaviour. Regardless of program level, men feel better able to manage behaviour (see also Specht et al., 2016). It may be that societally men are given more power to manage behaviour, and they feel this sense of control in the inclusive classroom. Only men planning to teach in the elementary system, however, felt more able to use inclusive instructional teaching strategies. Overall, elementary pre-service teachers felt more efficacious for managing behaviour and collaborating, regardless of gender.

\section{Teacher Efficacy}

Previous research has not examined which identified variables account for unique variance in teacher efficacy for inclusive practices. Observed group differences were not consistent across measures of beliefs and teacher efficacy. Further understanding which beliefs account for differences in areas of teacher efficacy is important, as the belief system is one that teacher educators can affect in pre-service education (Jao, 2017; Kavanoz et al., 2017). One observation across our regression analyses was that only a small proportion of the total variance was accounted for in each analysis. There are clearly further variables that were not included in this study, and that are perhaps yet to be identified in the field. Nonetheless, our analysis provides unique findings that can help to illuminate some similarities and differences concerning self-efficacy in elementary and secondary pre-service teachers.

Teacher efficacy for collaboration. Across program levels, having a friend with a disability and longer practice teaching placements with individuals with exceptionalities contributed to feeling more efficacious in being able to collaborate with parents, educational assistants, and other stakeholders in the education of students with diverse needs. Consistent with previous literature, all teacher candidates appear to benefit from experience with people with disabilities (e.g., Peebles \& Mendaglio, 2014); the current study highlights the positive influence of having had a friend with an exceptionality and of longer practicum experiences, regardless of program level.

Inclusion-related beliefs differentially predicted teacher efficacy for collaboration depending on whether individuals plan to teach in elementary or secondary settings. For 
pre-service teachers in the elementary program, those who have more student-centred beliefs feel better able to collaborate, as do those who see students as motivated by external factors such as grades. In the secondary program, teacher candidates who believe ability is a more malleable trait felt better able to collaborate within the education system.

Teacher efficacy for managing behaviour. In both elementary and secondary programs, the more teaching experiences individuals had with students with exceptionalities, the more efficacious they felt in managing behaviour. Pre-service teachers who have these lengthier practice-teaching experiences may be more likely to have encountered situations that they have had to manage, and thus have developed more skills and confidence in their ability to do so. Those who had a friend with a disability felt more able to manage behaviour, but only for pre-service teachers in the elementary program.

As was the case with teacher efficacy for collaboration, beliefs about learning and teaching contributed differentially to teacher efficacy for managing behaviour dependent upon program level. For elementary teacher candidates, those who believed more in student-centred learning felt better able to manage behaviour. For secondary participants, those who saw ability as more malleable than fixed, and those who believe students are motivated by external factors, felt better able to manage behaviour. Thus, secondary preservice teachers who view both students' learning and motivation as more dependent on environment, felt more efficacious in managing classroom behaviour.

Teacher efficacy for inclusive instructional practices. Both elementary- and secondary-level pre-service teachers who had more teaching practice with individuals with disabilities felt better able to deliver instruction using inclusive techniques; these would include designing instruction that reaches all learners, using small-group or partner work in the classroom, and designing varied and appropriate assessments. Across program levels, teacher candidates who saw learning as student centred felt better able to teach in inclusive ways. This consistency across programs is not surprising given that student-centred learning is a central tenet of inclusive education; that is, taking each students' instructional needs into account when designing teaching approaches is key to inclusive instructional practices.

For pre-service teachers in elementary programs, personal experience working or volunteering with individuals with disabilities contributed to efficacy for inclusive instructional practices. Perhaps individuals with this work or volunteer experience have had more of a coaching role, leading them to feel better about differentiating tasks and including all participants; however, it is not clear why only those in elementary programs show this connection. As was the case with efficacy for collaboration and managing behaviour, for pre-service teachers in secondary programs, those with beliefs that ability is more malleable than fixed felt better able to use inclusive instruction.

\section{Implications for Teacher Education}

In terms of the variables studied in this literature, there are some that are possible to change, and others that are not. We would argue that understanding group differences is important for all variables, as we can help to bring patterns to the awareness of teacher 
candidates. Identifying as a man or a woman is not something that can be controlled by educators or researchers, and we know that there is much overlap in scores for both genders; however, knowing that women tend to hold more inclusive beliefs than men may help a teacher candidate to ask whether that is the case for him or her and act accordingly.

We found that amount of experience with individuals with exceptionalities, both personal and professional, is an important contributor to high teacher efficacy across the domains examined for both elementary and secondary teacher candidates. As has been argued by others (e.g., Boyle, Topping, \& Jindal-Snape, 2013; Gökdere, 2012), one focus of teacher education programs should be on promoting positive experiences in inclusive educational settings for teacher candidates. Similarly, student-centred beliefs contributed to teacher efficacy for inclusive instructional practices across program levels. Student-centred approaches and beliefs will be important to promote with all teacher candidates. Important differences emerged, however, concerning which beliefs contributed to each area of teacher efficacy for secondary as compared to elementary programs. These findings have not been previously reported in the research literature and indicate a need to think about the ways in which teacher candidates in elementary or secondary streams are taught.

One aspect that contributed unique variance across all aspects of teacher efficacy for pre-service teachers in secondary programs was the Entity-Increment beliefs scale. Preservice teachers in secondary programs who more highly endorsed the premise that ability is malleable rather than fixed, felt more efficacious in all domains examined. Education programs may do well to explore ways to increase secondary teachercandidates' understanding that students' learning is not pre-determined, but rather is dependent on their classroom practices: in effect, to understand that they are responsible for student learning. Secondary teacher candidates may see themselves primarily as subject specialists teaching the curriculum, rather than as focused on how students learn; however, those who believe more strongly that students' learning abilities are malleable may be more likely to persevere in learning about inclusive practices. That is, they may be more likely to see ability as something over which they have control, and thus more likely to want to learn the techniques that will help them in doing so. Education programs with a greater emphasis on instructional techniques for diverse learners within core secondary subject areas (e.g., Universal Design for Learning and differentiated instruction), could improve secondary teacher candidates' competence and teacher efficacy for inclusive practices, as well as increase beliefs about the malleability of student learning.

Elementary pre-service teachers had overall higher beliefs on the Entity-Increment scale, but individual differences were not predictive of self-efficacy. For these elementary teacher candidates, individual differences in student-centred beliefs was a contributor to each of the three teacher efficacy domains examined. It may be that elementary programs tend to emphasize student-centred approaches more than secondary programs; however, there are still individual differences among these elementary candidates that are deserving of attention, as those whose beliefs are strongest in this domain feel more ready to teach in inclusive elementary classrooms.

In conclusion, in initial teacher education programs, it is important to provide the experiences and reflections graduates need in order to begin their journey of teaching 
prepared to be the best teachers that they can be. Beliefs that all students can learn and high teacher efficacy predict student achievement. The current study adds to an understanding of how experiences and beliefs contribute to teacher efficacy, and the differences in these relationships for future elementary and secondary teachers.

\section{References}

Avramidis, E., \& Norwich, B. (2002). Teachers' attitudes towards integration/inclusion: A review of the literature. European Journal of Special Needs Education, 17(2), 129-147. doi:10.1080/08856250210129056

Bacon, D. R. (2004). The contributions of reliability and pretests to effective assessment. Practical Assessment, Research \& Evaluation, 9(3), 1-8.

Bandura, A. (1977). Self-efficacy: Toward a unifying theory of behavioral change. Psychological Bulletin, 84, 191-215.

Bandura, A. (1994). Self-efficacy. In Encyclopedia of human behaviour (Vol. 4, pp. 71-81). New York, NY: Academic Press.

Bobek, B. L. (2009). Teacher resiliency: A key to career longevity. The Clearing House, 75(4), 202-205.

Boyle, C., Topping, K., \& Jindal-Snape, D. (2013). Teachers' attitudes towards inclusion in high schools. Teachers and Teaching: Theory and Practice, 19(5), 527-542. doi:10.1080/13540602.2013.827361

Brighton, C. M. (2003). The effects of middle school teachers' beliefs on classroom practices. Journal for the Education of the Gifted, 27, 177-206.

Caprara, G. V., Barbaranelli, C., Steca, P., \& Malone, P. S. (2006). Teachers' self-efficacy beliefs as determinants of job satisfaction and students' academic achievement: A study at the school level. Journal of School Psychology, 44(6), 473-490. doi:10.1016/j.jsp.2006.09.001

Chiner, E., \& Cardona, M. C. (2013). Inclusive education in Spain: How do skills, resources, and supports affect regular education teachers' perceptions of inclusion? International Journal of Inclusive Education, 17(5), 526-541. doi:10.1080/13603116.2012.689864

Gebhardt, M., Schwab, S., Krammer, M., \& Gegenfurtner, A. (2015). General and special education teachers' perceptions of teamwork in inclusive classrooms at elementary and secondary schools. Journal for Educational Research Online, 7, 129-146.

Glenn, C. (2018). The measurement of teachers' beliefs about ability: The development of the Beliefs About Learning and Teaching Questionnaire. Exceptionality Education International, 28(3), $51-66$.

Gökdere, M. (2012). A comparative study of the attitude, concern, and interaction levels of elementary school teachers and teacher candidates towards inclusive education. Educational Sciences: Theory and Practice, 12(4), 2800-2807.

Høigaard, R., Giske, R., \& Sundsli, K. (2012). Newly qualified teachers' work engagement and teacher efficacy influences on job satisfaction, burnout, and the intention to quit. European Journal of Teacher Education, 35(3), 347-357. doi:10.1080/02619768.2011.633993

Holzberger, D., Philipp, A., \& Kunter, M. (2013). How teachers' self-efficacy is related to instructional quality: A longitudinal analysis. Journal of Educational Psychology, 105(3), 774-786. doi:10.1037/a0032198

Jao, L. (2017). Shifting pre-service teachers' beliefs about mathematics teaching: The contextual situation of a mathematics methods course. International Journal of Science and Mathematics Education, 15, 895-914. doi:10.1007/s10763-016-9719-9 
Jordan, A. (2018). The Supporting Effective Teaching project: 1. Factors influencing student success in inclusive elementary classrooms. Exceptionality Education International, 28(3), 10-27.

Jordan, A., Glenn, C., \& McGhie-Richmond, D. (2010). The Supporting Effective Teacher (SET) project: The relationship of inclusive teaching practice to teachers' beliefs about disability and ability and about their roles as teachers. Teaching and Teacher Education, 26, 259-266. doi:10.1016/j.tate.2009.03.005

Jordan, A., Schwartz, E., \& McGhie-Richmond, D. (2009). Preparing teachers for inclusive classrooms. Teaching and Teacher Education, 25(4), 535-542. doi:10.1016/j.tate.2009.02.010

Jordan, A., \& Stanovich, P. (2003). Teachers' personal epistemological beliefs about students with disabilities as indicators of effective teaching practices. Journal of Research in Special Educational Needs, 3(1). doi:10.1111/j.1471-3802.2003.00184.x

Kavanoz, S., Yüksel, H. G., \& Varol, B. (2017). Evolvement of pre-service language teachers' beliefs through teacher education. International Journal of Progressive Education, 13, 119-135.

Klassen, R., \& Durksen, T. (2014). Weekly self-efficacy and work stress of pre-service teachers during the final teaching practicum: A mixed methods study. Learning and Instruction, 33, 158-169. doi:10.1016/j.learninstruc.2014.05.003

Klassen, R., Wilson, E., Siu, A. F. Y., Hannok, W., Wong, M. W., Wongsri, ... Jansem, A. (2013). Preservice teachers' work stress, self-efficacy, and occupational commitment in four countries. European Journal of Psychology of Education, 28(4), 1289-1309. doi:10.1007/s10212-012-0166-x

McGhie-Richmond, D., Irvine, A., Loreman, T., Cizman, J. L., \& Lupart, J. (2013). Teacher perspectives on inclusive education in rural Alberta, Canada. Canadian Journal of Education, $36,195-239$.

Miesera, S., \& Gebhardt, M. (2018). Inclusive vocational schools in Canada and Germany. A comparison of vocational pre-service teachers' attitudes, self-efficacy and experiences towards inclusive education, European Journal of Special Needs Education, 33(5), 707-722. doi:10.1080/08856257.2017.1421599

Palmer, D. (2006). Durability of changes in self-efficacy of preservice primary teachers. International Journal of Science Education, 28(6), 655-671. doi:10.1080/09500690500404599

Peebles, J. L., \& Mendaglio, S. (2014). The impact of direct experience on preservice teachers' selfefficacy for teaching in inclusive classrooms. International Journal of Inclusive Education, 18(12), 1321-1336. doi:10.1080/13603116.2014.899635

Province of New Brunswick. (2016). 10-year educational plan-Everyone at their best. Retrieved from http://www2.gnb.ca/content/dam/gnb/Departments/ed/pdf/K12/EveryoneAtTheirBest.pdf

Richardson, V. (2003). Pre-service teachers' beliefs. In J. Raths \& A. C. McAninch (Eds.), Teacher beliefs and classroom performance: The impact of teacher education (pp. 1-22). Greenwich, CT: Information Age Publishing.

Sharma, U., Forlin, C., \& Loreman, T. (2008). Impact of training on pre-service teachers' attitudes and concerns about inclusive education and sentiments about persons with disabilities. Disability \& Society, 23(7), 773-785. doi:10.1080/09687590802469271

Sharma, U., Loreman, T., \& Forlin, C. (2012). Measuring teacher efficacy to implement inclusive practices. Journal of Research in Special Educational Needs, 12, 12-21. doi:10.1111/j.14713802.2011.01200.x

Sharma, U., \& Sokal, L. (2015). The impact of a teacher education course on pre-service teachers' beliefs about inclusion: an international comparison. Journal of Research in Special Educational Needs, 15(4), 276-284. doi:10.1111/1471-3802.12043 
Shaw, J., \& Newton, J. (2014). Teacher retention and satisfaction with a servant leader as principal. Education, 135(1), 101-106.

Smith, D. D., \& Tyler, N. C. (2011). Effective inclusive education: Equipping education professionals with necessary skills and knowledge. Prospects, 41(3), 323-339. doi:10.1007/s11125-0119207-5

Sokal, L., Woloshyn, D., \& Funk-Unrau, S. (2013). How important is practicum to pre-service teacher development for inclusive teaching? Effects on efficacy in classroom management. Alberta Journal of Educational Research, 59(2), 285-298.

Specht, J., McGhie-Richmond, D., Loreman, T., Mirenda, P., Bennett, S., Gallagher, T., ... Cloutier, S. (2016). Teaching in inclusive classrooms: Efficacy and beliefs of Canadian preservice teachers. International Journal of Inclusive Education, 20(1), 1-15. doi:10.1080/13603116.2015.1059501

Stanovich, P., \& Jordan, A. (2004). The beliefs and practices of Canadian teachers about including students with special needs in their regular elementary classrooms. Exceptionality Education Canada, 14, 25-46.

Tabachnick, B. G., \& Fidell, L. S. (2007). Using multivariate statistics (5th ed.). New York, NY: Allyn and Bacon.

Todorovic, J., Stojiljkovic, S., Ristanic, S., \& Djigic, G. (2012). Attitudes toward inclusive education and dimensions of teacher's personality. Procedia-Social and Behavioral Sciences, 29, 426432. doi:10.1016/j.sbspro.2011.11.259

Woodcock, S., \& Hardy, I. (2017). Beyond the binary: Rethinking teachers' understandings of an engagement with inclusion. International Journal of Inclusive Education, 21(6), 667-686. doi: $10.1080 / 13603116.2016 .1251501$

Woolfolk Hoy, A., Hoy, W. K., \& Davis, H. (2009). Teachers' self-efficacy beliefs. In A. Wentzel \& A. Wigfield (Eds.), Handbook of motivation in school (pp. 627-654). Mahwah, NJ: Erlbaum.

Zee, M., \& Koomen, H. (2016). Teacher self-efficacy and its effects on classroom processes, student academic adjustment, and teacher well-being: A synthesis of 40 years of research. Revew of Educational Research, 86, 981-1015. doi:10.3102/0034654315626801

\section{Authors' Note}

This research was supported by SSHRC grant 435-2015-0128. Correspondence concerning this article should be addressed to Jacqueline Specht, Faculty of Education, Western University, 1137 Western Road, London, ON, N6G 1G7, Canada. Email: jspecht@uwo.ca 